\title{
Ruralidade e Regulação Ambiental: notas para um debate político-institucional ${ }^{*}$
}

Rodrigo Constante Martins ${ }^{* *}$

Resumo: Este artigo apresenta uma reflexão teórica sobre os temas sociológicos envolvidos no debate sobre ruralidade e regulação ambiental nas sociedades contemporâneas. Aborda as noções de território e desenvolvimento rural a partir de um enfoque político-institucional, buscando situar contextos societários em redes amplas de interação e construção de localidades, resguardando aquilo que as conjunturas sócio-políticas particulares preservam de suas relações com totalidades concretas.

Palavras-chave: Ruralidade; Regulação Ambiental, Desenvolvimento Rural

Classificação JEL: R52, R58, Q56, Q58

Abstract: This article presents a theoretical reflection of sociological themes involved in the debate on rurality and environmental regulation in contemporary societies. The paper discusses the notions of territory and rural development, starting from a political-institutional focus, attempting to locate the contexts of localities within wide nets of social reproduction. The

\footnotetext{
*A realização deste trabalho contou com auxílio da Fundação de Amparo à Pesquisa no Estado de São Paulo (FAPESP). O autor agradece as sugestões do parecerista anônimo da RER.

** Sociólogo. Bolsista de pós-doutorado FAPESP no Programa de Pós Graduação em Ciências Sociais da UFSCar. E-mail: rodrigo@iris.ufscar.br.
} 
paper's central argument emphasizes the importance of studies which insert the local power structures in the understanding of territorial dynamics.

Key-Works: Rurality; Environmental Regulation; Rural Development

JEL Classification: R52, R58, Q56, Q58

\section{Introdução}

Nos últimos anos, a literatura nas áreas de sociologia e economia rural vem recorrentemente acentuando a necessidade de fortes arranjos institucionais para a gestão sustentável - em termos sociais e ambientais - dos territórios rurais. De maneira geral, o debate tem apontado para a possibilidade de implementação de estratégias de desenvolvimento que sejam capazes de articular pactos territoriais entre diferentes atores envolvidos na trama sócio-política local.

Visando contribuir para tal debate, este artigo tem como objetivo abordar a temática agricultura e regulação ambiental à luz da discussão recente acerca das novas alternativas de desenvolvimento para as áreas rurais. Para tanto, o artigo divide-se em três sessões. Na primeira sessão apresenta alguns elementos da experiência européia de incorporação de instrumentos de regulação ambiental aos programas de sua Política Agrícola Comum. Também discute como tais iniciativas têm sido incorporadas naquele continente ao debate acerca de estratégias inovadoras de desenvolvimento rural. Na segunda sessão analisa como estas experiências européias vêm influenciando as reflexões da ciência social brasileira na problematização do que vem se convencionando chamar de novo rural brasileiro. Por fim, na terceira sessão aborda as particularidades das formações rurais brasileiras diante das inovações institucionais destacadas no debate sobre novas ruralidades.

\section{O Debate Europeu sobre a Ruralidade Contemporânea}

Em termos institucionais, a articulação entre metas sociais e ambientais no desenvolvimento agrícola vem ganhando abrangência internacional. Expressão importante deste movimento são as cláusulas ambientais 
criadas pela União Européia (UE) após a reforma de 1992 em sua Política Agrícola Comum (PAC). Instituídas inicialmente pela Regulação Agroambiental 2.078/92 e depois ampliadas pela resolução 1.257/99 do Conselho da UE, as cláusulas agroambientais têm como principal função a incorporação de compromissos ambientais na concessão das ajudas diretas aos agricultores dos Estados-membros. Sob a gerência de tais cláusulas, os agricultores incrementariam as ajudas financeiras recebidas da UE através da adesão a compromissos de emprego de métodos de produção agrícola compatíveis com a proteção ambiental e a preservação da paisagem do agroambiente $^{1}$. Por meio de tal política, a UE estaria influindo não somente sobre o perfil das práticas agrícolas dos países comunitários, mas também sobre os próprios níveis de renda das comunidades rurais.

Contudo, alguns estudos têm demonstrado as assimetrias dos resultados atingidos pelos programas agroambientais de alguns países da UE. Wilson et. al. (1999), comparando as políticas agroambientais da Alemanha e da Espanha, ressaltam que o relativo sucesso dos programas alemães deve-se fundamentalmente a dois fatores não excludentes, quais sejam, o aporte de recursos financeiros que o governo alemão se dispôs a investir nos programas agro-ambientais e à capacidade de gestão administrativa de tais programas, estruturados de forma descentralizada e participativa. Já na Espanha, além do baixo aporte de recursos para a execução dos programas agroambientais, os embates políticos estabelecidos entre as várias instâncias de implementação dos programas fizeram com que a agricultura espanhola pouco avançasse em termos de mudança de suas práticas produtivas. A este respeito, Mazorra (2001) destaca a disputa corporativa entre as instâncias de implementação dos programas espanhóis. No mais das vezes, tais disputas expõem o choque de interesses entre autoridades agrícolas - que buscam resguardar seus espaços de contato direto com os agricultores, através das consultas técnicas e do fornecimento dos tradicionais subsídios públicos - e as autoridades ambientais, mais atreladas à estrutura bucrático-estatal e prontas a disputar espaços de intervenção

\footnotetext{
${ }^{1}$ As cláusulas agroambientais não são obrigatórias nos contratos de ajudas diretas aos agricultores. Estes compromissos, firmados sob regime contratual de livre adesão entre os agricultores e o Estado, possuem um período mínimo de 5 anos de duração, sendo que seus custos de implementação são partilhados entre o Estado-membro proponente e a UE, que limita sua participação em, no máximo, $75 \%$ do orçamento total do programa.
} 
entre os agricultores para a disseminação de técnicas agrícolas distintas daquelas do receituário agronômico tradicional.

Outro indicador das assimetrias entre países na implementação de programas agroambientais diz respeito à conjuntura sócio-política regional no interior do continente. Segundo Moyano e Garrido (1997), nas regiões norte e central da Europa, a pressão tanto dos governos nacionais quanto de parte considerável das sociedades locais, criou circunstâncias favoráveis de envolvimento dos agricultores em tais programas. Ademais, os agricultores das regiões supra - produtores de cereais, leite, carne bovina, etc. - são os principais beneficiários da PAC, concentrando a maior parte dos recursos e subsídios fornecidos pelos instrumentos de intervenção, fato este que vem influenciando sobremaneira a disposição destes agricultores para o cumprimento de cláusulas agroambientais. Já nos países mediterrâneos - produtores de vinhos, azeite, frutas e hortícolas -, a presença de uma agricultura menos intensiva, com níveis de contaminação ambiental inferiores aos da agricultura do centro-norte do continente, beneficiaria pouco, segundo os autores, a mobilização social para a adesão dos agricultores aos programas agroambientais. De um modo geral, haveria na região mediterrânea do continente uma busca constante, tanto por parte das populações rurais quanto por parte dos governos nacionais, de alternativas à baixa competitividade da agricultura regional, fato que, no mais das vezes, reservaria um interesse secundário destes à formulação de programas agroambientais.

As respostas distintas verificadas no concernente à implementação de programas agroambientais têm sido interpretadas, por grupos distintos de estudiosos, à luz do debate recente sobre as alternativas de desenvolvimento para as áreas rurais da UE (WINTER, 2000). Por esta razão, as assimetrias acentuadas em análises comparativas de experiências nacionais têm revelado menos um caminho padrão de alteração de práticas agrícolas do que a importância da variável localidade na experimentação de políticas públicas para as áreas rurais. Até mesmo porque, nos dias atuais, como nos esclarece Saraceno (1999), o mundo rural europeu é bem mais amplo que a agricultura européia. Isto significa que mesmo as estratégias de intervenção da PAC visando a sustentabilidade das práticas de produção agrícola - como é o caso dos programas agroambientais - devem ser enquadrados em um novo conceito de ruralidade, qual 
seja, aquele que supere o olhar setorial e ponha-se a problematizar as possibilidades de desenvolvimento territorial das áreas rurais.

Esta perspectiva tem sido partilhada por vários estudiosos da temática rural na Europa. Seja apontando a pertinência de novos recortes espaciais para a apreensão da dinâmica das economias locais (MARSDEN et al, 1993), seja sugerindo análises sobre as possibilidades de governança da diversidade de interesses em maturação no mundo rural (GOODWIN, 1998), existe um pressuposto geral de que não há padrões ou modelos a serem apontados para o desenvolvimento local; tal desenvolvimento deve ser construído com base nas demandas e características locais, tendo como referência àquelas variáveis externas que encerram as relações da localidade em totalidades mais amplas de produção de valor.

Sob tal contexto, Hervieu (1993) acentua que a nova ruralidade européia compreende estruturas complexas de composição de atividades distintas de produção de valor. Por esta razão, seriam equivocadas tanto as iniciativas de elaboração de instrumentos de políticas públicas rurais que busquem alternativas de desenvolvimento exclusivamente em função da dinâmica agrícola, quanto àquelas concepções ingênuas e imediatistas - estimuladas em grande medida pelas estatísticas de diminuição relativa da renda agrícola - de que o mundo rural teria se emancipado da agricultura. Para o autor, haveria a necessidade de realização de novos esforços analíticos de compreensão do complexo motor de desenvolvimento econômico e social das localidades sem o desprezo da ocupação agrícola do território.

Yliskylã-Peuralahti (2003) ressalta que, do ponto de vista da gestão ambiental, faz-se necessária a construção de esferas públicas que visem a composição dos interesses agrícolas com os dos demais setores sociais interessados na dinamização das estruturas de produção de valor nas áreas rurais. Além disso, para a autora, a discussão em torno da própria gestão ambiental deve relativizar, em nível local, a ênfase sobre questões técnicas que, além de criarem ilusões de que estariam acima dos interesses de grupos sociais, também não contribuem para que a diversidade sócio-cultural dos territórios possa favorecer a gestão local tanto dos interesses sociais quanto dos recursos naturais ${ }^{2}$.

\footnotetext{
${ }^{2}$ Em grande medida, esta perspectiva de construção local do desenvolvimento vem sendo o marco referencial dos programas LEADER (Ligações entre Ações de Desenvolvimento da
} 
A despeito das distintas realidades históricas, este debate europeu acerca da nova ruralidade e das formas agrícolas de exploração dos recursos naturais vem influenciando, no Brasil, a discussão sobre alternativas de desenvolvimento para as áreas rurais do país. Em parte, tal influência se deve ao fato de que o processo de diversificação das atividades produtivas nas áreas rurais não é uma particularidade européia. Conforme veremos adiante, são vários os estudos que têm conseguido detectar a proliferação de atividades rurais sem vínculos com a produção agrícola em várias regiões brasileiras. Além disso, a própria necessidade de reversão dos danos ambientais causados pelo apropriacionismo industrial da agricultura nacional vem justificando reflexões sobre as possibilidades de disseminação de técnicas agroecológicas nas áreas rurais do país 3 .

\section{O Debate sobre Novas Ruralidades no Brasil}

Parte das transformações operadas nos espaços europeus de sociabilidade rural, sobretudo aquelas decorrentes da retração do emprego agrícola, também se verificam, com intensidades distintas, em algumas regiões do Brasil. Esse processo de ocupação do espaço rural com outras atividades que não a agricultura-pecuária ganha relevância em um contexto onde a aceleração do ritmo de vida urbano, em condições de crescente depreciação da qualidade de vida, tem atribuído ao campo uma dimensão de ambiente de revigoramento das relações entre indivíduo e natureza, com o culto das formas ecológicas e das raízes culturais das

Economia Rural) no continente europeu. Criados pela OCDE, em 1991, com o propósito de dinamizar as áreas rurais classificadas de "menos favorecidas", um dos eixos de ação dos programas LEADER diz respeito justamente à conservação do ambiente natural e das heranças culturais destas áreas. Para pormenores dos objetivos e resultados atingidos pelos programas, ver LEADER European Observatory (1999).

${ }^{3}$ A noção de apropriacionismo industrial da agricultura, Goodman, Sorj e Wilkinson (1990), visa teorizar o movimento de apropriação industrial de frações do processo de produção agrícola superando restrições ambientais - sendo que uma de suas principais expressões seria a mecanização dos instrumentos de trabalho necessários ao preparo do solo. Nesta mesma reflexão, os autores apresentam ainda a noção de substitucionismo industrial, que expressaria em nível analítico o momento onde o produto agrícola passaria cada vez mais a ser substituído por produtos industriais - evidência esta que poderia ser notada a partir do desenvolvimento recente da indústria alimentícia. 
comunidades rurais. Diante disso, tais atividades têm se firmado como alternativa de ocupação e renda no meio rural.

Laurenti e Del Grossi (2000) deram números a este importante avanço das atividades não agrícolas no mundo rural brasileiro. De acordo com os autores, a taxa de crescimento da população rural ocupada em atividades agrícolas entre os anos de 1992 e 1997 foi negativa de 2,2\%, enquanto que o crescimento da população rural ocupada em atividades não-agrícolas no mesmo período foi positivo de 2,5\%. No caso do Estado de São Paulo, ao longo do mesmo período, a taxa anual de crescimento da população ocupada em atividades não-agrícolas foi de $2,4 \%$, enquanto que a da população rural ocupada em atividades agrícolas foi negativa de $5,6 \%$. Ainda segundo os autores, os ramos de atividade mais dinâmicos em termos de geração de empregos no próprio meio rural brasileiro ao longo deste período foram a prestação de serviços, a indústria de transformação, o comércio de mercadorias, transporte e comunicação, além da indústria da construção civil.

De acordo com Silva (2001b), estas transformações no emprego e na renda rural dificultariam, assim como no continente europeu, a delimitação do que seria urbano e do que seria rural em uma perspectiva espacial. A continuidade estabelecida entre estes dois espaços ao longo das últimas décadas - cuja expressão maior, até então, se manifestaria nos chamados Complexos Agroindustriais - acentuar-se-ia agora no transbordamento das atividades produtivas do mundo urbano, que, sem vínculos com a produção agrícola, buscariam cada vez mais espaços de atuação no mundo rural.

Para Veiga (2001b), um dos fatores responsáveis pela dificuldade de incorporação, no âmbito da construção de políticas públicas, das reais amplitudes das atividades distribuídas nos espaços rurais, diria respeito aos atuais critérios de corte normativo rural-urbano. Para este autor, a definição oficial de divisão territorial - definição esta advinda do Estado Novo (Lei Federal no 311 de 1938) -, ao estabelecer que todas as sedes municipais são necessariamente áreas urbanas, teria criado a ficção estatística de que, em 2000, cerca de $81 \%$ da população brasileira residiria em áreas urbanas. Entretanto, como sustentar tal dado se, como é sabido, $70 \%$ dos municípios brasileiros possuem densidades demográficas inferiores a $40 \mathrm{hab} / \mathrm{km}^{2}$ ? 
Se tomarmos como referência os critérios de divisão territorial da OCDE - que definem como urbanizadas as áreas com densidades demográficas superiores a 150hab/ $\mathrm{km}^{2}$-, em 2000, o Brasil teria, segundo Veiga (2001b), apenas 411 dos seus 5.507 municípios classificados como urbanos. A constatação desta situação, evidentemente, daria um novo dimensionamento para o debate sobre a ruralidade e, mais especificamente, para o tratamento da importância relativa da agricultura nas áreas rurais do país. Ademais, a própria temática da gestão dos recursos naturais em áreas rurais ganharia novos contornos, com a incorporação de atividades não-agrícolas nas análises sobre as estruturas locais de produção de valor.

Não obstante a concordância acerca do surgimento de novas atividades e interesses sociais nas áreas rurais do país, as formas de interpretação de tal realidade têm sido distintas entre os estudiosos nacionais dos processos de ruralidade. No caso das novas possibilidades de geração de emprego e renda nas áreas rurais, Veiga (2001a, 2001b), por exemplo, enfatiza a necessidade da diversificação das economias regionais, posto que o próprio agribusiness não possuiria condições estruturais de gerar renda, de maneira descentralizada, para as populações rurais. Tal diversificação poderia resultar, segundo o autor, da exploração de vantagens comparativas e competitivas dos territórios. Neste caso, a articulação de municípios, atuando em esferas micro-regionais de fortalecimento de redes diversificadas de produção de valor, poderia constituir-se em eixo de desenvolvimento para distintas localidades.

Para Veiga, a evolução da pluriatividade seria de grande importância em circunstâncias de diversificação produtiva, posto que serviria de indicador do nível de proliferação de novas atividades geradoras de emprego nas áreas rurais ${ }^{4}$. Ademais, a dinamização de tais áreas deveria estabelecer, em seu curso, uma sinergia entre biodiversidade e empreendedorismo rural. Segundo o autor, esta sinergia seria produzida através de uma espécie de capitalização das restrições ambientais; ou seja, a própria promoção da biodiversidade poderia se constituir em serviço ambiental, em atrativo para empreendimentos que explorem, de modo sustentável, a riqueza ecossistêmica da localidade.

\footnotetext{
${ }^{4}$ A propósito de análises sobre as situações de pluriatividade das áreas rurais do país, ver Carneiro (1998) e Schneider (2003).
} 
Já para Silva (2001a, 2001b), a transformação fundamental para minar as desigualdades existentes nas áreas rurais do país diria respeito à criação de novas oportunidades e de novas institucionalidades. Para o autor, a diversificação das economias regionais, tal como propõe Veiga, pode responder por incrementos econômicos, mas não necessariamente por avanços no campo da cidadania das populações rurais. Neste sentido, às novas oportunidades a que se refere o autor dizem respeito não só à geração de emprego e renda para as áreas menos favorecidas, mas também a oportunidades de acesso aos itens identificados como requisitos fundamentais de cidadania nas áreas urbanas, tais como o acesso à água tratada, luz elétrica e esgotamento, por exemplo.

No que diz respeito à pluriatividade, o autor destaca que, em suas formas atuais, esta tem sido, no mais das vezes, um indicador das desigualdades sociais nas áreas rurais. Isto porque a grande diferença entre as causas da pluriatividade no Brasil e nos países centrais da Europa e mesmo nos Estados Unidos é que, aqui, ela não resulta de um crescimento da produtividade do trabalho agropecuário, que liberaria produtores e trabalhadores agrícolas para o desenvolvimento de outras atividades agrícolas e/ou não-agrícolas. Ao contrário disso, no Brasil, a pluriatividade tem sido uma estratégia de sobrevivência das famílias agrícolas mais pobres. Para Silva (2001a), uma das expressões desta característica da pluriatividade brasileira é o crescimento, dentro das atividades de prestação de serviços nas áreas rurais, do trabalho doméstico assalariado de baixa remuneração. Segundo o autor, isto indicaria, ao contrário do que supõe Veiga, não a descentralização do emprego no campo, mas, antes de mais nada, os altos níveis de concentração de renda do país e a manutenção do baixíssimo nível do salário nas áreas rurais.

No campo das novas institucionalidades, Silva ressalta o "vácuo", em termos de regulação pública, deixado pela limitação dos instrumentos de intervenção do Estado em forma de políticas agrícolas e agrárias. Neste caso, ainda que atreladas a um corte eminentemente setorial, as políticas estatais de atuação nos espaços rurais cumpriam um importante papel de equalização parcial das demandas das populações do campo. A redução do alcance das políticas de Estado fez com que, de acordo com o autor, tanto a agricultura quanto as novas atividades não-agrícolas se desenvolvessem sem marcos regulatórios bem definidos. 
Para Campanhola e Silva (2000), o "novo rural brasileiro" demanda o surgimento de instâncias institucionais descentralizadas que possibilitem a participação das comunidades locais no planejamento e na gestão dos recursos humanos, econômicos e ambientais dos territórios. Este novo rural requereria, portanto, a criação de instrumentos de planejamento local para a gestão sócio-econômica e ambiental dos recursos territoriais. Em certo sentido, trata-se de uma sugestão próxima daquela feita por Veiga (2001a) acerca da dinamização das áreas rurais. Assim como no caso deste último, Campanhola e Silva ressaltam a importância da integração de escalas físico-ambientais no planejamento do uso sócio-econômico dos espaços. Neste aspecto em específico, a diferença entre os autores reside na formulação de Veiga acerca das ecotaxas como instrumento de arrecadação e gestão ambiental nas localidades.

Ao tratar do planejamento local como alternativa de criação de novas oportunidades para as áreas rurais, Campanhola e Silva (2000) destacam a importância dos processos de "orquestração" dos diversos interesses dos grupos sociais envolvidos no território. Neste caso, seria fundamental, sob a ótica dos autores, a ampliação e consolidação de instâncias descentralizadas de tomada de decisões sobre os rumos do território. A localidade, assim, ganharia importância como força aglutinadora de composição de interesses sociais, ainda que sob o risco de reproduzir formas de organização "que apenas mascaram as práticas tradicionais e, na maioria das vezes, clientelistas, corporativistas e autoritárias de poder local" (CAMPANHOLA; SILVA, 2000: 74).

Também voltado à temática do desenvolvimento rural sob a ótica da localidade, Abramovay (2000) aponta o fenômeno da proximidade social como aspecto distintivo nas iniciativas de concentração de interesses em um dado território. Esta proximidade seria a base da construção do que o autor chama de "novo sujeito coletivo do desenvolvimento", que exprimiria a capacidade de articulação dos interesses sociais dispostos em uma determinada região. A este processo de construção de um sujeito coletivo através da busca de proximidades de interesses sociais o autor dá o nome de fortalecimento do capital social do território.

Para Abramovay, o nível de constituição deste capital social depende, dentre outros, das "tramas" territoriais enraizadas histórica e regionalmente. Tais "tramas" comporiam o tecido social do território e revelariam 
interesses, configurações políticas e identidades distintas. Nesta perspectiva, o autor refere-se às experiências européias, impulsionadas pela OCDE, como portadoras de importantes lições para a reflexão nacional acerca da dimensão territorial do desenvolvimento rural (ABRAMOVAY, 2000; 2002). Os Programas LEADER, por exemplo, são considerados inovadores pelo autor justamente por conceberem o desenvolvimento em escala territorial e não setorial, o que também imporia a necessidade de criação de um ambiente de negociação constante entre os grupos envolvidos na "trama” territorial.

\section{Temporalidades e Instituições no Rural Brasileiro}

Sem dúvidas, a emergência da dimensão territorial nas estratégias de desenvolvimento para as áreas rurais vem se revelando como elemento fundamental para a superação da corrente redução do rural ao agrícola. Não obstante este avanço em termos de planejamento regional, segue sendo de suma importância a retomada das características históricas das formações sócio-políticas das áreas rurais brasileiras para a avaliação das propostas de gestão dos espaços rurais. Por certo, a experiência dos países da OCDE - sobretudo dos países europeus, portadores de novas iniciativas institucionais, como, por exemplo, as resoluções agroambientais - revelam mecanismos interessantes de incorporação de medidas de gestão ambiental nas áreas rurais, sejam estas áreas ainda predominantemente agrícolas, sejam elas economicamente dinamizadas por novos segmentos produtivos e/ou por setores de serviços. Todavia, cada formação social possui um modo particular de filtragem e incorporação de processos modernizantes. Isto significa que, no caso brasileiro, as histórias distintas de nossas várias sociedades rurais deverão compor quadros heterogêneos de iniciativas locais de desenvolvimento e de incorporação da temática ambiental na gestão dos próprios territórios.

Com efeito, não existem indícios de que o surgimento de atividades não-agrícolas tenha modificado substancialmente as estruturas patrimonialistas de grande parte das relações de reprodução social das formações rurais. Também não há informações que apontem para trajetórias de melhoramento dos níveis de educação, atendimento à saúde e acesso a esgoto e água tratada nas comunidades rurais do país. Mesmo no âmbito 
do mercado de trabalho, as características das atividades não-agrícolas nas áreas rurais do país demonstram que as populações rurais permanecem à mercê de soluções imediatistas para reproduzirem-se como força de trabalho. A este respeito, é sintomático, por exemplo, constatarmos que, dentre as ocupações que mais empregam em números absolutos no campo esteja o serviço doméstico, seguido da ocupação de pedreiro (LAURENTI; DEL GROSSI, 2000).

Ainda que representem, em certo sentido, a emergência de padrões alternativos e modernos de geração de emprego e renda nas áreas rurais, ainda é preciso considerar as atividades não-agrícolas dificilmente provocarão, per si, profundas transformações nas práticas sociais mais tradicionais das comunidades rurais. Isto porque a sociedade brasileira demonstra, historicamente, modos peculiares de submissão do moderno ao tradicional (MARTINS, 1999). A ordem patrimonialista, por exemplo, ainda bastante presente nas formações rurais do país, assegura, inclusive através da dominação de estruturas políticas - como as prefeituras municipais, por exemplo -, o predomínio dos interesses de grupos sociais territorialmente estabelecidos. Neste sentido, não é raro encontrar em municípios rurais o domínio pleno de lideranças agrícolas nas instâncias municipais e regionais de estímulo ao desenvolvimento rural (MARTINS, 2004; VALENCIO e MARTINS, 2004). No mais das vezes, este domínio resulta na instrumentalização do aparato público em prol de interesses setoriais ${ }^{5}$.

Este tipo de circunstância traz ênfase empírica à afirmação de Martins (1999: 30), para quem

[...] na sociedade brasileira, a modernização se dá no marco da tradição, o progresso ocorre no marco da ordem. Portanto, as transformações sociais e políticas são lentas, não se baseiam em acentuadas e

\footnotetext{
${ }^{5}$ Esta situação de permanente intrumentalização das práticas administrativas não é, aliás, fenômeno recende na história brasileira. Como bem nos mostra Franco (1997), tal situação constituiu-se em um dos traços característicos da afirmação do poder público local após a Independência nacional. Através do estudo das práticas sociais da velha civilização do café na região do Vale do Paraíba, a autora destrinchou as maneiras pelas quais o caráter abstrato e geral da ação pública - preceito jurídico fundamental da estrutura burocrática do poder público - foi constantemente submetido à situação de interesse dos próprios agentes de governo. Ainda que sob circunstâncias diversas, esta face patrimonial do uso da força normativa permanece requerendo, a nosso ver, especial atenção por parte dos estudiosos da temática da localidade no país.
} 
súbitas rupturas sociais, culturais, econômicas e institucionais. O novo surge sempre como um desdobramento do velho: foi o rei de Portugal, em nome da nobreza, que suspendeu o medieval regime de sesmarias na distribuição de terras; (...) foram os senhores de escravos que aboliram a escravidão [...]. Trata-se, portanto, de uma sociedade estruturalmente peculiar, cuja dinâmica não se explica por processos políticos e históricos dos modelos clássicos. (grifo do autor)

Por conta destas especificidades, faz-se necessária a realização de esforços analíticos para a interpretação, na constituição dos processos de desenvolvimento, da formação do moderno conciliada com a presença viva e ativa de processos sociais tradicionais ${ }^{6}$. No caso do desenvolvimento rural, em particular, torna-se premente a necessidade da análise das relações políticas e institucionais que vem se estabelecendo entre lideranças agrícolas e novos empreendedores nas áreas rurais. Este esforço interpretativo permitirá compreender as formas particulares de manifestação de novas ruralidades em localidades distintas. Permitirá, portanto, compreender a dinâmica contraditória do espaço, seus arranjos e/ou conflitos endógenos que, em certa medida, definirão suas formas de integração com outros territórios.

Embora, como vimos, haja esforços de vários autores na ênfase da importância do território/localidade nos processos de desenvolvimento e diversificação das áreas rurais, não se deve perder de vista que, entre o local e o geral, há uma relação dialética de formação. Isto significa que, ao estar circunscrita em totalidades mais amplas, a localidade é, além de agente determinante, também espaço determinado pelo próprio movimento da totalidade ${ }^{7}$. É neste âmbito de interação com dimensões mais amplas da totalidade que se definem, por exemplo, suas relações econômicas e sócio-culturais com os centros urbanos. Deste modo, não se trata de apreender a localidade como derivação ou como simples

\footnotetext{
${ }^{6}$ Cumpre ressaltar que as relações entre o moderno e o tradicional aqui destacadas não estão conceitualmente referidas nas análises dualistas de dinâmicas sociais. Ao contrário disso, neste texto, moderno e tradicional somente indicam o caráter complexo das relações que comumente envolvem a construção de novos contextos para a disputa de hegemonias entre distintos grupos sociais.

${ }^{7}$ A propósito do emprego da noção marxiana de totalidade concreta em estudos sócioambientais, ver Martins e Valencio (2003) e Martins (2004).
} 
conseqüência de estruturas, mas de considerá-la como elemento em constante movimento na formação da realidade concreta, formada por múltiplas determinações e canais de interação.

Esta perspectiva das relações do local com o movimento da totalidade social nos permite considerar que questões institucionais - tais como as relacionadas à regulação ambiental e à participação do Estado na gestão pública do território - podem ter influência decisiva nos rumos da localidade. Aqui, outra especificidade nacional evidencia a complexidade de relações que envolvem a gestão dos espaços rurais. Diferentemente dos casos americano e europeu, o Brasil não possui tradição na condução de políticas públicas estrategicamente direcionadas às suas áreas rurais. Talvez também por essa razão, temas como a multifuncionalidade e a capacidade de gestão ambiental de pequenos agricultores sejam de difícil assimilação em nossa sociedade. Como já demonstraram Pinto e Bergamasco (2000) em estudo de caso, a pequena produção familiar, por exemplo, é vista pelo próprio corpo técnico da extensão rural do Estado de São Paulo não como uma alternativa de agricultura sustentável, mas, pelo contrário, como um resíduo frente à agricultura tecnificada, integrada a grandes complexos agroindustriais ${ }^{8}$.

Em qualquer que seja o viés de análise sobre estratégias de desenvolvimento rural, a transformação dos atuais padrões de uso agrícola dos recursos naturais ocupa posição central de reflexão. A despeito do crescimento do emprego não-agrícola, a agricultura permanece como sendo a principal usuária dos recursos ecossistêmicos nas áreas rurais do país. Em razão disso, as possibilidades de fixação de novas frentes de produção de valor nestes espaços também dependerão do nível de adequação sócio-ambiental da agricultura, visto que a expansão de tais frentes associa-se, dentre outros, à própria paisagem característica das áreas rurais. Assim, atividades direcionadas aos "nichos de mercado" - como aquelas associadas ao turismo esportivo e ao lazer - dependerão diretamente dos esforços do setor agrícola para a preservação e/ou recuperação das paisagens rurais.

\footnotetext{
${ }^{8} \mathrm{O}$ referido estudo foi desenvolvido junto aos segmentos de técnicos que estão diretamente inseridos no planejamento e execução da ação extensionista no estado, quais sejam, os diretores regionais, responsáveis pelos Escritórios de Desenvolvimento Rural (EDRs) que compõem a estrutura da CATI em todo o estado, e os técnicos que atuam nas Casas da Agricultura (escritórios localizados nos municípios), tanto aqueles do quadro estadual como aqueles contratados via convênios de municipalização.
} 


\section{Considerações Finais}

Os temas destacados pelos debates europeu e nacional acerca da construção de novas estratégias de desenvolvimento rural sugerem, como conseqüência de análise, tanto a necessidade de articulação entre a participação dos grupos sociais locais na elaboração e condução de novas estratégias de desenvolvimento rural, quanto inovações institucionais a serem empreendidas no sentido da distinção sócio-ambiental deste desenvolvimento.

Tendo por referência os termos de tal análise, é possível afirmar que, no Brasil, o caso da adequação sócio-ambiental da agricultura - fundamental para a sustentabilidade não só do próprio setor, mas também para as demais atividades que seguem crescendo nas áreas rurais - dependerá, em grande medida, da capacidade de diálogo e da condução de ações compassadas entre as instâncias nacional e local de poder e os próprios agricultores. Sobretudo do ponto de vista institucional, é fundamental que haja articulação entre políticas ambientais, que visem formas de regulação dos usos do solo e da água, e políticas agrícolas e agrárias fortemente comprometidas com a justiça fundiária, a geração de tecnologias limpas e a definição de metas sócio-ambientais a serem atingidas pelo setor.

Este diálogo institucional, por sua vez, pode articular-se às metas sociais estabelecidas territorialmente, provenientes do planejamento integrado da gestão dos recursos naturais com os anseios de desenvolvimento das forças sociais estabelecidas num dado espaço. Neste caso, a regulação social dos movimentos de produção de valores excedentes fixados no território surge como condição sine qua non para a definição de alternativas sustentáveis de uso social dos processos ecológicos. Menos por representar uma suposta unidade dos interesses locais do que por expressar as contradições territoriais, tal regulação pode gerar, além de experiências de governança (como no caso europeu), também novos espelhos sobre a construção de memórias e projetos no âmbito da localidade.

Do exposto, cumpre uma vez mais enfatizar que a construção de intervenções coordenadas, com metas agrícolas e agrárias que considerem a redução das disparidades sociais; a combinação de tais metas com a adoção de políticas de inovação e disseminação de tecnologias 
baseadas em critérios de seletividade ambiental; e, por fim, o fortalecimento da participação das minorias locais nas esferas de controle social do uso dos recursos naturais, são alguns dos impasses a serem enfrentados para a qualificação sócio-ambiental das estratégias de desenvolvimento das áreas rurais do país.

\section{Referências bibliográficas}

ABRAMOVAY, R. O Capital Social dos Territórios: repensando o desenvolvimento rural. Revista de Economia Aplicada, V.4, N² 2, p. 379-396, 2000. ABRAMOVAY, R. Subsídios e Multifuncionalidade na Política Agrícola Européia. Revista de Economia e Sociologia Rural. São Paulo, vol. 40, $\mathrm{n}^{\circ} 2$, p. 235-264, 2002.

CAMPANHOLA, C.; SILVA, J.G. Diretrizes de Políticas Públicas para o Novo Rural Brasileiro: incorporando a noção de desenvolvimento local. In CAMPANHOLA, Clayton; SILVA, José G. (edits) O Novo Rural Brasileiro: políticas públicas. Vol.4, Jaguariúna-SP: Embrapa, 2000.

CARNEIRO, M.J. (1998) Camponeses, Agricultores e Pluriatividade. Rio de Janeiro, Contra Capa Livraria, 1998.

FRANCO, M.S.C. Homens Livres na Ordem Escravocrata. $4^{\text {a }}$ ed. São Paulo: Ed. UNESP, 1997.

GOODMAN, D., SORJ, B.; WILKINSON, J. Da Lavoura às Biotecnologias: agricultura e indústria no sistema internacional. Rio de Janeiro: Campus, 1990.

GOODWIN, M. The Governance of Rural Areas: some emerging research issues and agendas. Journal of Rural Studies, vol.14, $\mathrm{n}^{\circ} 1$, p. 5-12, 1998.

HERVIEU, B., Les Champs du Futur. Paris, Bourdin Francois Eds, 1993.

LAURENTI, A.C.; DEL GROSSI, M.E. A Evolução das Pessoas Ocupadas nas Atividades Agrícolas e Não Agrícolas nas Áreas Rurais do Brasil. In CAMPANHOLA, Clayton; SILVA, José G. (editores) O Novo Rural Brasileiro: uma análise nacional e regional. Vol.1, Jaguariúna-SP: Embrapa, 2000. 
LEADER EUROPEAN OBSERTATORY. Territorial competitiveness: creating a territorial development strategy in light of the LEADER experience. Dossier $n^{\circ} 6$ LEADER European Observatory, 1999.

MARSDEN, T. et. al. Constructing the Countryside. London: University College London Press, 1993.

MARTINS, J.S. O Poder do Atraso: ensaios de sociologia da história lenta. $2^{a}$ ed. São Paulo: Hucitec, 1999.

MARTINS, R.C. Agricultura, Gestão dos Recursos Hídricos e Desenvolvimento Rural: a convergência necessária. In VALENCIO, Norma F.; MARTINS, Rodrigo C.; LEME, Alessandro André (orgs) Uso e Gestão de Recursos Hídricos no Brasil: velhos e novos desafios para a cidadania. São Carlos-SP: RiMa, 2001.

MARTINS, R.C.; VALENCIO, N.F. A Concretude da Moderna Crise Sócioambiental. In MARTINS, Rodrigo C.; VALENCIO, Norma F. (orgs) Uso e Gestão dos Recursos Hídricos no Brasil - Vol. 2: desafios teóricos e político-institucionais. São Carlos-SP: RiMa, 2003.

MARTINS, R.C. A Construção Social do Valor Econômico da Água: estudo sociológico sobre agricultura, ruralidade e valoração ambiental no Estado de São Paulo. Tese (Doutorado). PPG-SEA, Universidade de São Paulo, 2004.

MAZORRA, A.P. Agri-Environmental Policy in Spain: the agenda of sociopolitical developments at the national end local levels. Journal of Rural Studies (17), p. 81-97, 2001.

MOYANO, E.; GARRIDO, F. Actores Sociales y Política Agroambiental en la Unión Europea. In SHIKI, S.; GRAZIANO DA SILVA, J.; ORTEGA, A.C. (orgs) Agricultura, Meio Ambiente e Sustentabilidade do Cerrado Brasileiro. Uberlândia-MG: UFU, 1997.

PINTO, A.G.; BERGAMASCO, S.M. A Construção de uma Nova Extensão Rural: o potencial dos técnicos da rede pública de São Paulo. Anais do X Congresso Mundial de Sociologia Rural - Rio de Janeiro: IRSA, 2000.

SARACENO, E. O Conceito de Ruralidade: problemas de definição em escala européia Roma: Programa de Seminários INEA, 1999. 
SCHNEIDER, S. Teoria social, agricultura familiar e pluriatividade. Revista Brasileira de Ciências Sociais, Vol.18, n.51, p.99-122, fev 2003.

SILVA, J.G. Quem Precisa de uma Estratégia de Desenvolvimento? Série Textos para Discussão n² 2 . Brasília-DF: NEAD, 2001 a.

SILVA, J.G. Velhos e Novos Mitos do Rural Brasileiro. Estudos Avançados, vol.14, ${ }^{\circ} 43$, set/dez., p.37-50, 2001b.

SILVA, J.G.; DEL GROSSI, M.E. A Pluriatividade na Agropecuária Brasileira em 1995. Poços de Caldas-MG: XXXVI Congresso Brasileiro de Economia e Sociologia Rural, 1998.

VALENCIO, N.F.; MARTINS, R.C. Novas Institucionalidades na Gestão de Águas e Poder Local: os limites territoriais da democracia decisória. Interações: Revista Internacional de Desenvolvimento Local. Campo Grande-MS, v. 5, n. 8, p. 55-70, 2004.

VEIGA, J.E. O Brasil Rural Precisa de uma estratégia de Desenvolvimento. Série Textos para Discussão n ${ }^{0} 1$. Brasília-DF: NEAD, $2001 \mathrm{a}$.

VEIGA, J.E. O Brasil Rural Ainda não Encontrou seu Eixo de Desenvolvimento. Estudos Avançados, vol.14, nº43, set/dez., p.101-119, 2001b.

YLISKYLÄ-PEURALAHTI, J. Biodiversity - a new spatial challenge for Finnish agri-environmental policies? Journal of Rural Studies, (19), p. 215-231, 2003.

WILSON, G.A.; PETERSEN, J.E.; HÖLL, A. E.U. Member State Responses to Agri-Environment Regulation 2078/92/EEC - towards a conceptual framework?. Geoforum (30): Pergamon, p.185-202, 1999.

WINTER, M. Strong Policy or Weak Policy ? The Environmental Impact of The 1992 Reforms to the CAP Arable Regime in Great Britain. Journal of Rural Studies (16), p. 47-59, 2000.

Recebido em agosto de 2004 e revisto em fevereiro de 2005. 